\title{
Test Design Calculations II
}

\author{
M. Gerassimenko
}

June 1, 2000

U.S. Department of Energy

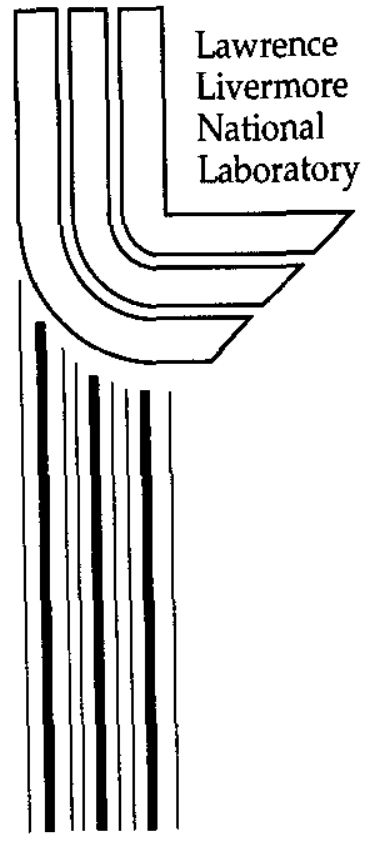




\section{DISCLAIMER}

This document was prepared as an account of work sponsored by an agency of the United States Government. Neither the United States Government nor the University of California nor any of their employees, makes any warranty, express or implied, or assumes any legal liability or responsibility for the accuracy, completeness, or usefulness of any information, apparatus, product, or process disclosed, or represents that its use would not infringe privately owned rights. Reference herein to any specific commercial product, process, or service by trade name, trademark, manufacturer, or otherwise, does not necessarily constitute or imply its endorsement, recommendation, or favoring by the United States Government or the University of California. The views and opinions of authors expressed herein do not necessarily state or reflect those of the United States Government or the University of California, and shall not be used for advertising or product endorsement purposes.

Work performed under the auspices of the U.S. Department of Energy by the University of California Lawrence Livermore National Laboratory under Contract W-7405-Eng-48. This work was performed under the sponsorship of the USASMDC with Dr. Robert Becker as the technical manager under MIPER W31RPD-0-C5204.

This report has been reproduced directly from the best available copy.

Available to DOE and DOE contractors from the Office of Scientific and Technical Information

P.O. Box 62, Oak Ridge, TN 37831

Prices available from (423) 576-8401 http://apollo.osti.gov/bridge/

Available to the public from the National Technical Information Service

U.S. Department of Commerce 5285 Port Royal Rd., Springfield, VA 22161 http://www.ntis.gov/

OR

Lawrence Livermore National Laboratory Technical Information Department's Digital Library http://www.llnl.gov/tid/Library.html 


\section{UCRL-ID-140082}

\section{Test Design Calculations II}

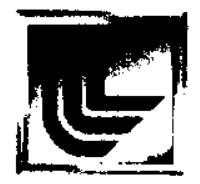

Michel Gerassimenko

Lawrence Livermore National Laboratory Livermore, CA 94551

June 2000 


\section{Introduction:}

In an earlier report ${ }^{1}$, we presented results of modeling calculations for one simple geometry that represents an experiment potentially to be performed at Sandia National Laboratory, which is examining equation of state issues of interest to the National Missile Defense Program. In the earlier report, we showed snapshots of calculations with two different initial zone dimensions for Gruneisen EOS and LEOS. We also showed pressure profiles at various locations in a witness plate out of the way of direct projectile impact, but hit by shrapnel generated during impact. It was found that the pressure profiles exhibit strong dependence on location, zone size, and equation of state. In this report we examine the overall momentum impacted to the witness plate. This momentum shows negligible dependence on the equation of state and some dependence on zone size.

\section{Geometry of the modeled test:}

The test is the normal impact of an aluminum sphere $0.6 \mathrm{~cm}$ in diameter onto a silicate phenolic flat plate target $0.5 \mathrm{~cm}$ thick at $7 \mathrm{~km} / \mathrm{s}$ initial projectile velocity. An aluminum witness plate $0.42 \mathrm{~cm}$ thick is placed out of the way of direct projectile impact, but close enough to be impacted by shrapnel generated by projectile impact. The witness plate is tilted by $45^{\circ}$ with respect to the projectile velocity vector. Its corner nearest the velocity vector is $1.3 \mathrm{~cm}$ away from the velocity vector through the projectile center, and $2 \mathrm{~cm}$ away from the back of the target.

\section{Modeling:}

Modeling is done with the ALE3D code. The modeling uses two symmetry planes normal to each other, both containing the projectile velocity vector. The model setup and two views in the symmetry planes are shown in Figure 1. Zoning is initially uniform with $0.1 \mathrm{~cm}$ resolution, but material weights are used to concentrate zoning in the projectile and target.

Calculations were performed with two different sets of equations of state. In the first set, all three materials are represented by Gruneisen equations of 
state. The aluminum is taken to be 6061-T6 alloy; the silicate phenolic EOS is a polynomial fit to the $U_{s}-U_{p}$ data at $U_{s}$ up to $8.2 \mathrm{~km} / \mathrm{s}$. Steinberg Guinan constitutive properties are used for the aluminum alloy and for the silicate phenolic. A second set of calculations used the same constitutive properties, but . the equation of state for the projectile and target were tabular ones (LEOS), developed at LLNL, that treat all phases of the material. We performed two more calculations with an initially uniform zoning with $0.05 \mathrm{~cm}$ resolution, i.e., eight times more zones. Angled views of the projectile, target, and witness plate are shown at $14 \mu \mathrm{s}$ for all four calculations in Figure 2.

\section{Witness plate momentum:}

The witness plate momentum along all three axes for the two lower resolution calculations is shown in Figure 3. There is virtually no dependence of the momentum components on equation of state.

The witness plate momentum along all three axes for the two higher resolution calculations is shown in Figure 4. Again, there is no dependence of the momentum components on equation of state.

The witness plate momentum along all the three axes for the Gruneisen EOS calculations is shown in Figure 5, for the LEOS calculations in Figure 6. The momentum components show some zoning dependence, but the dependence is not large at this level of resolution.

\section{Conclusions:}

We have performed modeling calculations for a potential simple non-one -dimensional experiment. An aluminum sphere normally impacts a silicate phenolic plate, and a witness plate, located out of the way of direct projectile impact, is hit by shrapnel generated during projectile impact. Calculations were done with two sets of EOS: Gruneisen for all materials and LEOS for the projectile and target and at two different resolution levels: initially uniform zoning of $0.1 \mathrm{~cm}$ and $0.05 \mathrm{~cm}$. In an earlier document, we reported strong dependence of the calculated pressure profiles, at various locations in the witness plate, on location, zone size, and equation of state. In this report, we show the 
momentum imparted to the witness plate to be weakly dependent on zoning and essentially independent of EOS. We expect lethality at the location of the witness plate to be correlated with momentum imparted to it. For the case examined here, we, therefore, expect the choice of Gruneisen versus LEOS to have little impact on lethality.

\section{Reference} 2000 .

${ }^{1}$ M. Gerassimenko, Test Design Calculations, UCRL-ID-138233, March 

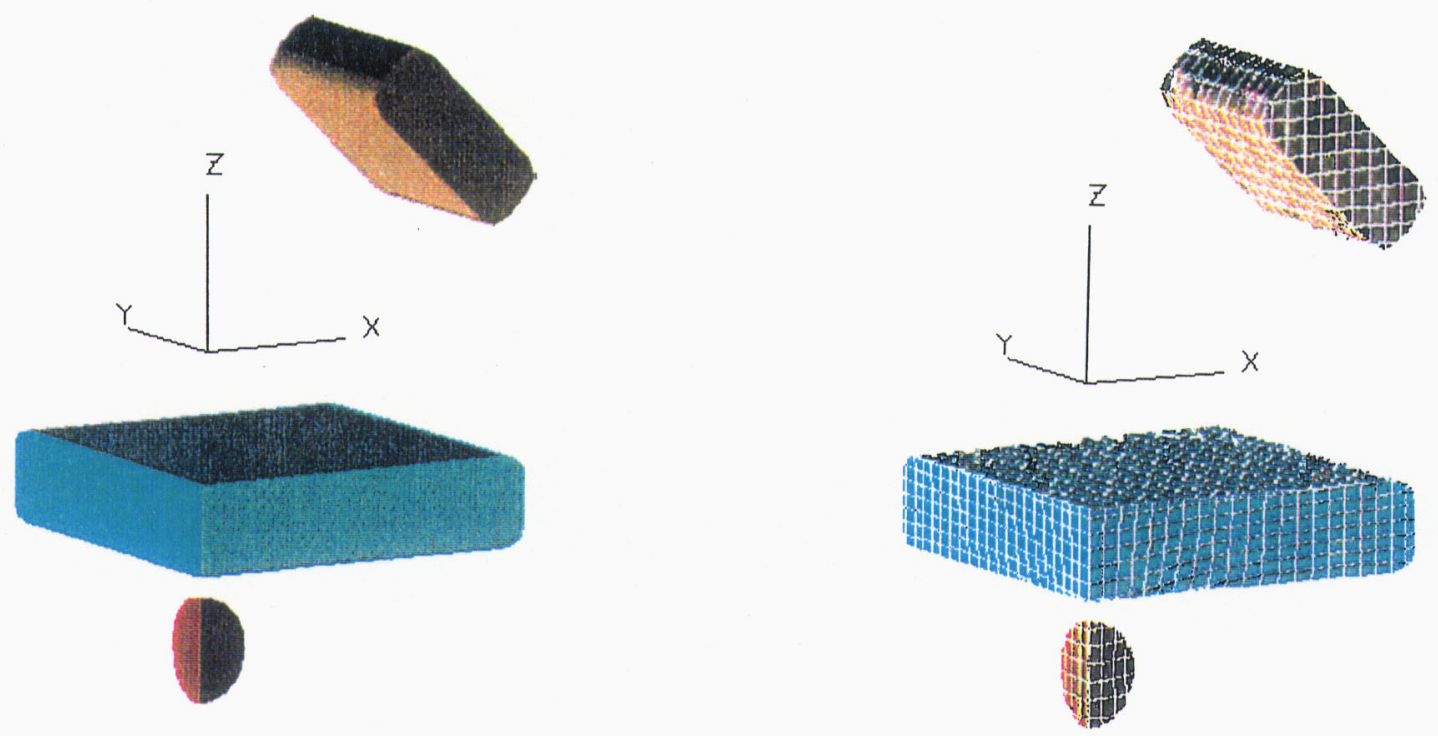

$30^{\circ}$ left $10^{\circ}$ up view

$30^{\circ}$ left $10^{\circ}$ up view
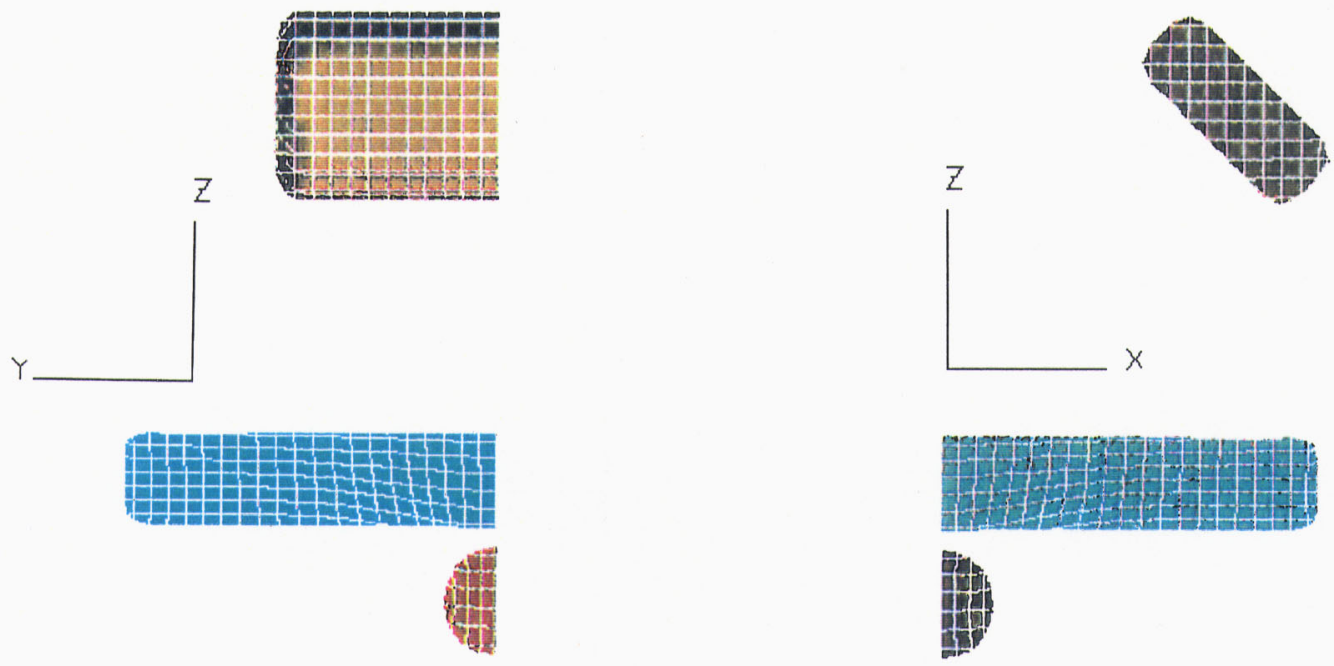

$90^{\circ}$ left $0^{\circ}$ view

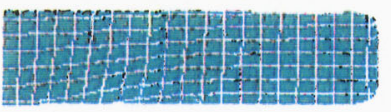

$+1$

$0^{\circ} 0^{\circ}$ view

Figure 1: Geometry of the test modeling. The two symmetry planes are shown in the bottom two pictures. Zoning is shown in three pictures. 

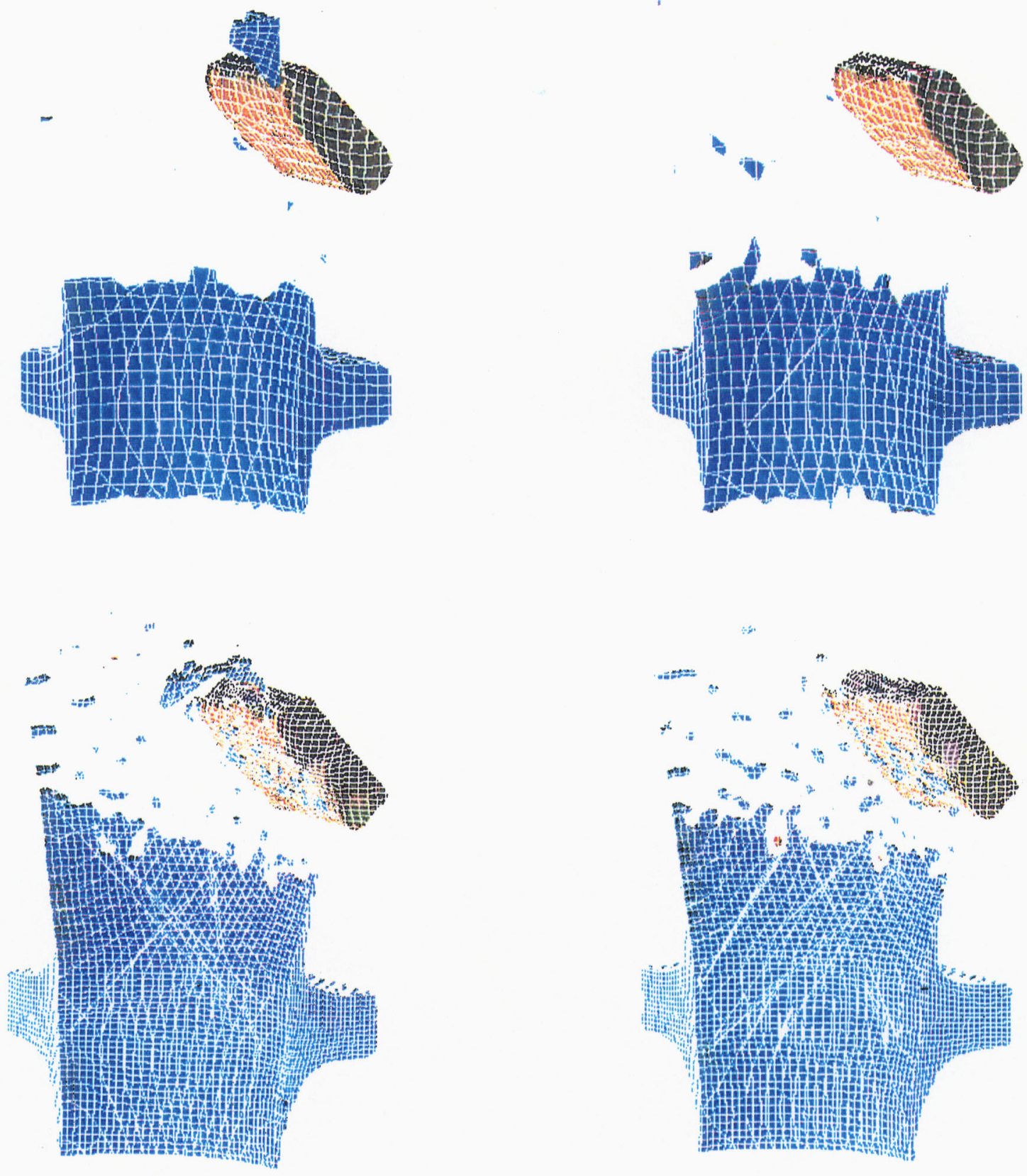

Figure 2: View of the calculations near the end of the runs at $14 \mu$ s with zoning indicated. Gruneisen EOS calculations are on the left, LEOS calculations on the right. 


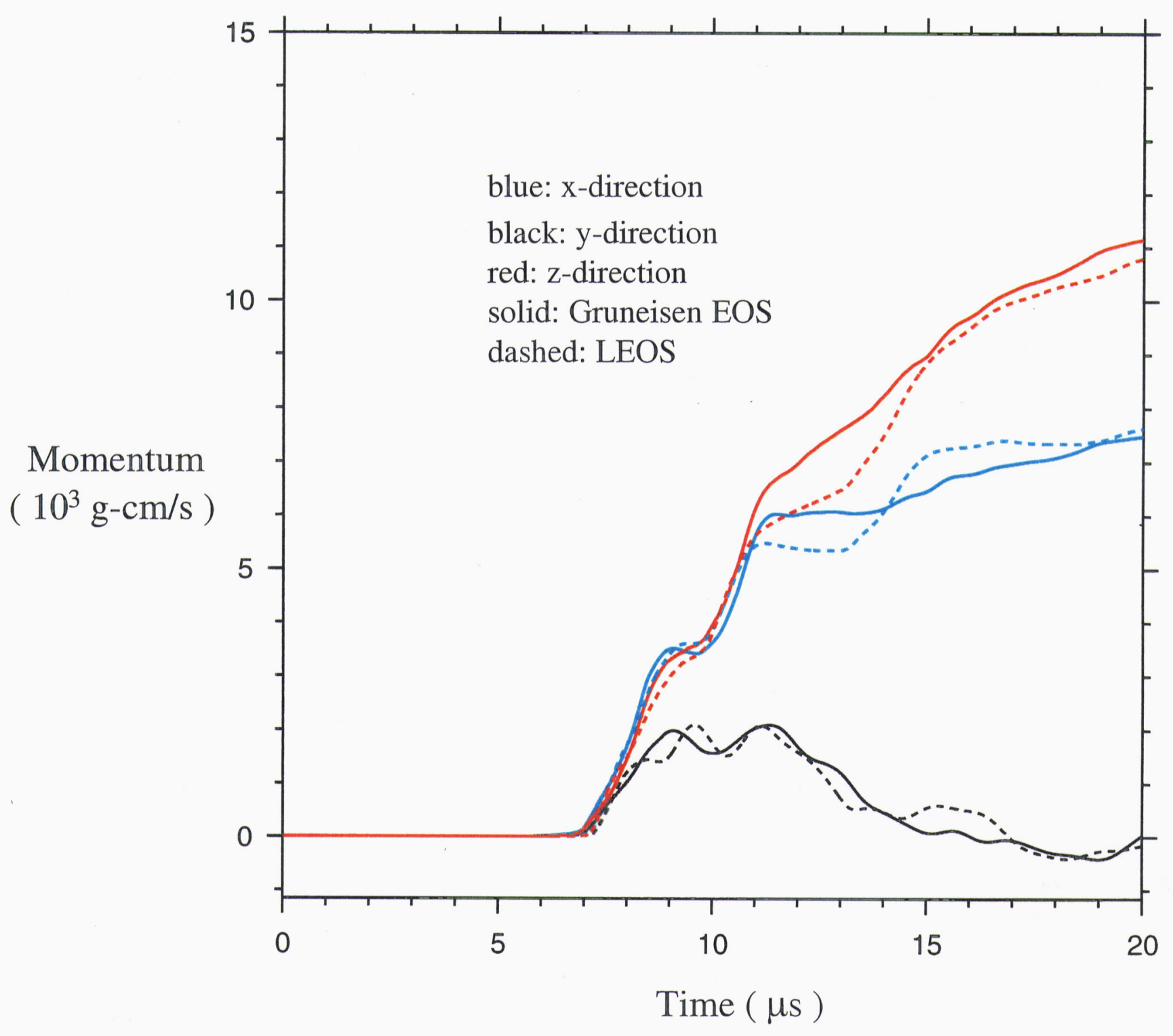

Figure 3: Momentum imparted to the witness plate along all three axes for the initially $0.1 \mathrm{~cm}$ resolution calculations. 


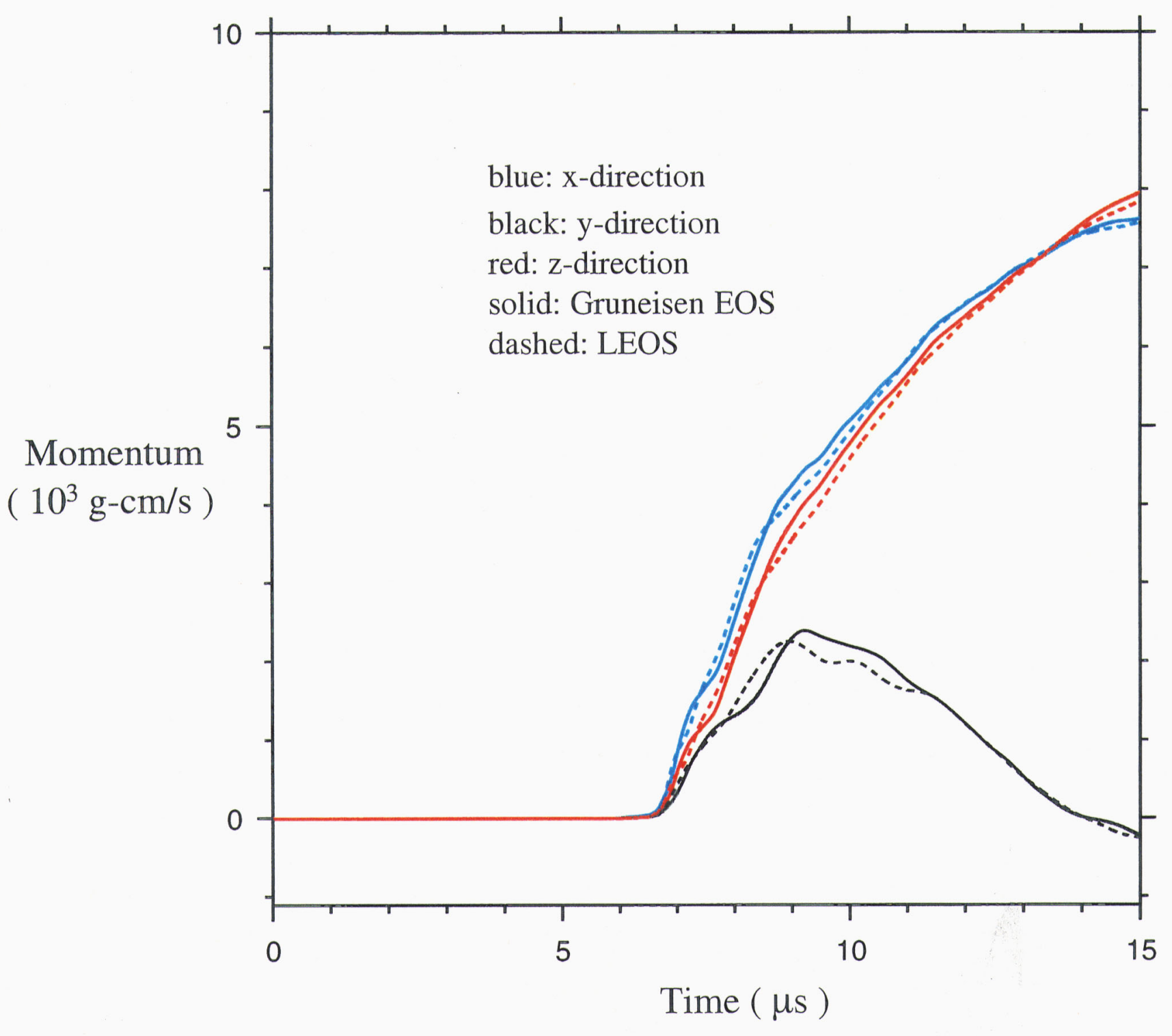

Figure 4: Momentum imparted to the witness plate along all three axes for the initially $0.05 \mathrm{~cm}$ resolution calculations. 


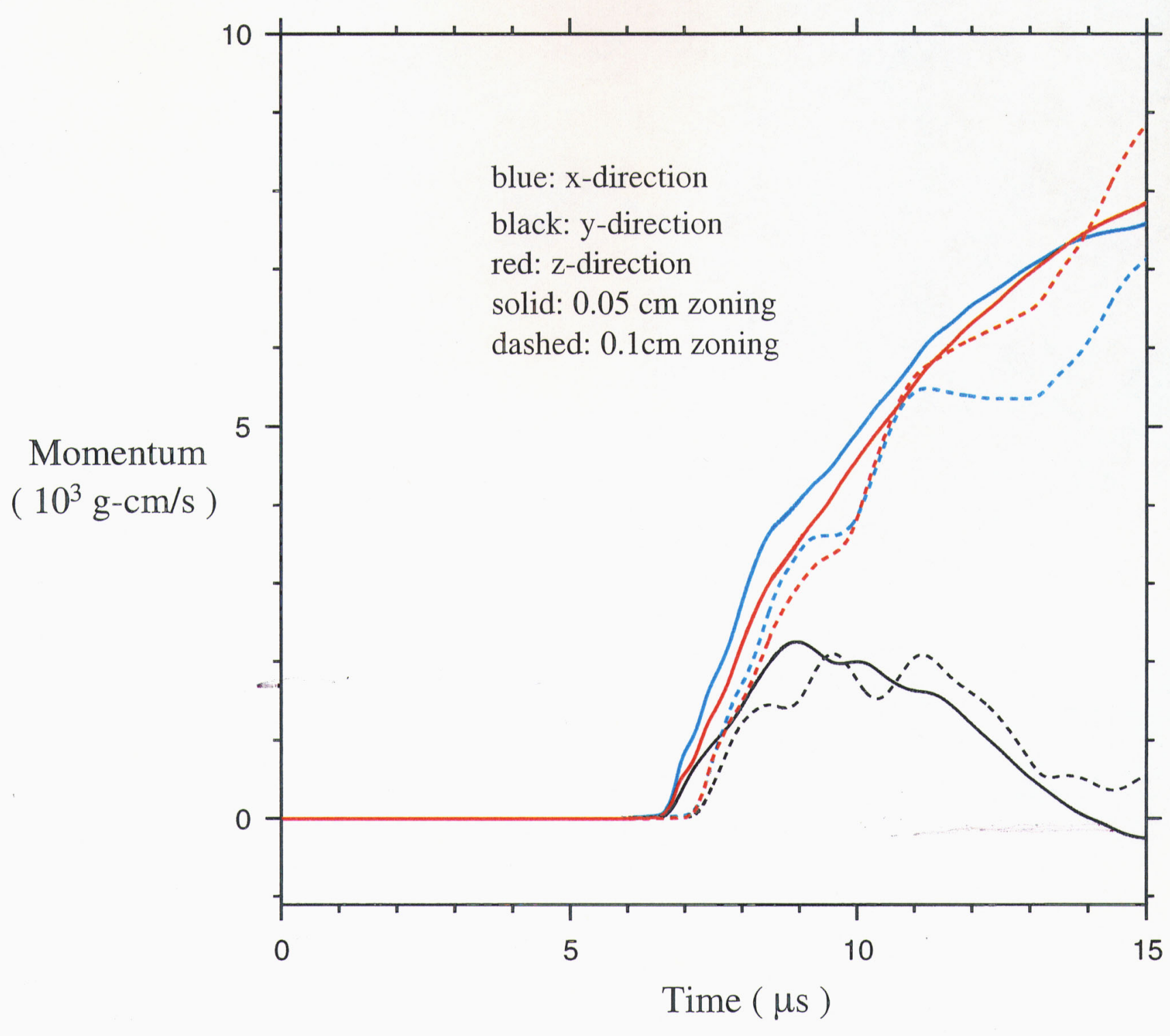

Figure 5: Momentum imparted to the witness plate along all three axes for the Gruneisen EOS calculations. 


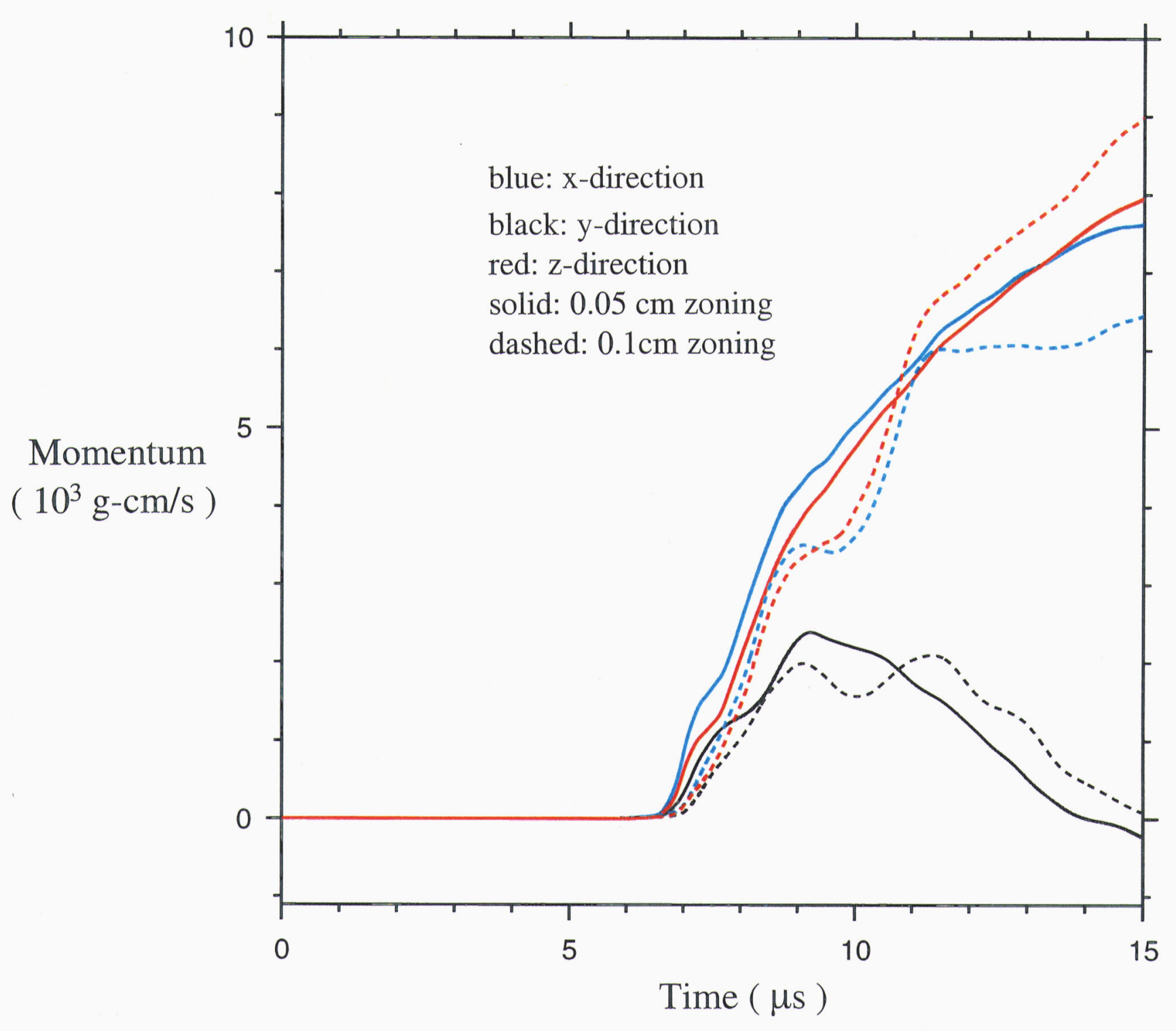

Figure 6: Momentum imparted to the witness plate along all three axes for the LEOS calculations. 